\title{
La filosofía política de la segunda escolástica: entre tomismo y modernidad
}

\author{
Political philosophy of the second scholasticism: \\ between thomism and modernity
}

GonZalo Letelier Widow

Universidad de los Andes, Chile gletelier@uandes.cl

DOI: https://doi.org/10.15366/bp2021.26.007

Bajo Palabra. II Época. No26. Pgs: 141-160 
Recibido: 10-09-2020

Aceptado: 24-09-2020

\section{Resumen}

La diferencia de la filosofía política de la segunda escolástica con la de los clásicos modernos es sobre todo metafísica. Las semejanzas argumentales, históricamente fundamentales, resultan teóricamente irrelevantes respecto de esta diferencia, cuyo principio primario es la centralidad de un bien (realmente) común, manifestado en una ética teleológica centrada en la virtud. El artículo revisa cómo, por esta razón, una serie de tópicos que la primera modernidad articula como aspectos de un único problema político, todavía constituyen para estos autores cuestiones independientes, solo vinculadas en la idea de bien común político.

Palabras clave: Soto, Vitoria, Suárez, modernidad, tomismo, bien común.

\section{Abstract}

The difference between the political philosophy of the second school and that of the modern classics is above all metaphysical. The historically fundamental argumentative similarities are theoretically irrelevant to this difference, whose primary principle is the centrality of a (really) common good, manifested in a teleological ethic centred on virtue. The article reviews how, for this reason, a series of topics that early modernity articulates as aspects of a single political problem still constitute for these authors independent questions, only linked in the idea of political common good.

Keywords: Soto, Vitoria, Suárez, Modernity, Thomism, common good. 
En una PeQueña y ambiciosa obra, André de Muralt afirma que el aristotelismo constituye el principio de inteligibilidad de la filosofía moderna ${ }^{1}$. De un modo bastante más discreto, intentaré sostener aquí que, con todas sus diferencias, el tomismo es el principio de inteligibilidad de la filosofía política de los autores de la segunda escolástica.

A primera vista, se trata de una tesis bastante pacífica, si no directamente de una perogrullada: Tomás de Aquino es considerado como el autor de referencia por toda la escuela, siendo este quizás su elemento de unidad más evidente. Sin embargo, con frecuencia la literatura reciente tiende a desestimar los elementos "tomistas" de Suárez, a subrayar la herencia nominalista de los dominicos del primer período, sobre todo de Vitoria, y a subrayar lo que hay de continuidad de toda la escuela con la filosofía moderna, en una lectura retrospectiva que, si bien puede estar históricamente justificada, no pocas veces distorsiona el sentido original de sus tesis. De modo que al menos dos cuestiones en particular tienden a relativizar la tesis propuesta aquí: por una parte, el hecho de que estos autores, y especialmente Suárez, son antecedentes directos de la filosofía política clásica de la modernidad, al punto de que muchos de sus razonamientos son reproducidos casi literalmente por Grocio o Locke, y, en segundo lugar, la presencia de un cierto eclecticismo en que confluyen argumentos de muy diverso origen: no solo de Tomás de Aquino, que es la fuente reconocida como canónica, sino también de una lectura humanista de los clásicos grecolatinos, de la obra de Escoto y de Ockham, del derecho romano y de la misma tradición jurídico política de los diversos reinos que constituyeron España.

Por mi parte, argumentaré que el sentido más auténtico y los aspectos más unitarios de los autores del periodo, más allá de las influencias que ejercieran posteriormente, e incluso en aquello en lo que se apartan de Tomás, deben ser leídos y comprendidos en el contexto de la síntesis tomista; más en concreto, desde la idea de bien común como principio del orden político.

Voy a argumentar esta tesis intentando mostrar cómo una serie de tópicos y problemas que tienden a confluir en una única esquematización arquetípica en los clásicos de la modernidad -a saber: origen de la autoridad política, explicación de la

\footnotetext{
${ }_{1}$ De Muralt, André. La estructura de la filosofía politica moderna: sus orígenes medievales en Escoto, Ockham y Suárez. Madrid, AKAL, 2002. Se trata, sin nombrarlo, del clásico trascendental verum, según el cual lo verdadero es principio de inteligibilidad, incluso respecto del error.
} 
asociación política, justificación de la propiedad privada y fundamentación de la obligación jurídica-, son, en cambio, en Tomás de Aquino y en estos autores, problemas decrecientemente distintos e independientes, que tienden paulatinamente a vincularse, pero que solo se comprenden en virtud de su respectiva referencia a un concepto de bien común político fundamentalmente común y unitario. Si la tesis es plausible, bastará esbozar los aspectos más relevantes y menos controvertidos de las posiciones de Vitoria, Soto y Suárez sobre estos tópicos para concluir que, aun constituyéndose como antecedentes inmediatos de la formulación moderna, pertenecen a un mundo y a una mentalidad completamente diversa; quizás no pre-moderna, pero sí propia de "otra" modernidad.

En otros términos, se trata de distinguir claramente la continuidad histórico-filosófica con los clásicos modernos, suficientemente probada por la literatura especializada, de una mucho más cuestionable proximidad teórica, con la cual se la suele confundir. Esta diferencia teórica es estrictamente metafísica, no solo filosófico-práctica; con lo cual, las evidentes semejanzas con los autores modernos en la estructura argumental pasan a ser accidentales, porque sirven a otros fines dentro de otra lógica.

En síntesis, y pese a las profundas diferencias metafísicas de Suárez con Tomás de Aquino, sostendré que el concepto (tomista) de bien común político es principio de inteligibilidad de los más importantes nudos teóricos de la filosofía jurídico-política de Vitoria, Soto y Suárez, tomados como arquetipos de la escuela.

\section{Los polos dialécticos: arquetipo moderno y aristotelismo tomista}

EL ARQUETIPO MODERNO DE UNA FUNDAMENTACIÓN DEL ORDEN POLÍTICO, con todos sus matices y diferencias desde Hobbes hasta Rousseau o incluso Kant, pasando por Pufendorf y Locke, plantea un grupo de hombres, titulares de derechos individuales -entre los que descuella la propiedad privada- que eligen constituir una autoridad política capaz de erogar normas vinculantes para garantizar esos mismos intereses. En este contexto, con las debidas precisiones, los tópicos de la legitimidad de la autoridad política, el fin de la asociación, la fundamentación y límites de la propiedad privada y la justificación de la obligación jurídica confluyen en un único acto legitimante (en algunos casos, propiamente fundante) de la sociedad política, que asume la forma de un pacto.

El esquema que propone Locke en su Second treatise on civil government, que resulta ser, en este contexto, el ejemplo más adecuado, plantea una agrupación de hombres que se asocian políticamente para proteger su propiedad privada, instituyendo una autoridad cuya función primordial es, precisamente, tutelar derechos individuales me- 
diante las leyes, las cuales, en la mejor tradición hobbesiana, no son mucho más que preceptos respaldados por la fuerza. En este contexto, la sociedad civil resulta ser un artefacto útil para conservar la propiedad - "esto es, su vida, libertad y bienes" ${ }^{2}$, la cual pasa a ser, en consecuencia, causa de la asociación, fin de la autoridad política, fuente de la obligación y, en fin, sustrato y forma última de cualquier tipo de vínculo social.

El esquema tomista, por su parte, difícilmente puede ser más opuesto. Sociabilidad humana, autoridad política y propiedad privada son tematizados en pasajes muy distintos de la obra de Tomás de Aquino, sin ningún tipo de vinculación temática ${ }^{3}$. El tema de la obligación, por su parte, solo es tratado de modo indirecto e incidental a lo largo de su obra, excepto por S. Th. q.96, a.4, en que se pregunta por la obligatoriedad de la ley humana ${ }^{4}$. Ciertamente, es posible indentificar con precisión el modo en que cada uno de estos tópicos se relaciona con todos los demás; pero la ratio o inteligibilidad de cada uno es independiente; $y$, en cualquier caso, el principio que los vincula no tiene relación alguna con un eventual pacto, sino que se halla en el bien común político.

Respecto de la sociabilidad humana, la posición de Tomás de Aquino sigue puntualmente el esquema aristotélico, remitiendo en innumerables ocasiones al clásico pasaje de Política I:

"La razón por la cual el hombre es un ser social, más que cualquier abeja y que cualquier animal gregario, es evidente: la naturaleza, como decimos, no hace nada en vano, y el hombre es el único animal que tiene palabra. Pues la voz es signo del dolor y del placer, y por eso la poseen también los demás animales, porque su naturaleza llega hasta tener sensación de dolor y de placer e indicársela unos a otros. Pero la palabra es para manifestar lo conveniente y lo perjudicial, así como lo justo y lo injusto. Y esto es lo propio del hombre frente a los demás animales: poseer, él solo, el sentido del bien y del mal, de lo justo y de lo injusto, y de los demás valores, y la participación comunitaria de estas cosas constituye la casa y la ciudad" 5 .

\footnotetext{
${ }^{2}$ Locke, John. Two treatises of government, Cambridge, Cambridge University Press, 2015, Second book VII, p. 87; para el planteamiento general sintetizado aquí, vid. especialmente VIII, 95-99 y IX, 123-127.

3 Para un eficaz compendio de estos lugares, muy ilustrativo de la mentada dispersión, cfr. Widow, Juan Antonio. "Escritos políticos de santo Tomás de Aquino". Estudios Públicos, 57, 1995, pp. 345-409; la propiedad privada, por su parte, es tematizada, sobre todo, en la cuestión relativa al hurto de la Summa Theologiae (II-II, q.66; todos los texto de Tomás de Aquino se citan según la edición de Alarcón, Enrique, www.corpusthomisticum.org; en adelante, las citas de esta obra serán abreviadas $S$. Th.).

${ }^{4}$ El término utilizado en este lugar no es "obligari" sino "imponere necessitatem in foro conscientiae". Como se puede corroborar mediante una rápida consulta a cualquiera de los diversos Índices de la obra de Tomás de Aquino, los términos obligari u obligatio son siempre usados respecto de un problema distinto de la misma obligación, que no es nunca considerada en sí misma; cfr., por ejemplo, la clásica Tabula Aurea de Pedro de Bérgamo (Paoline, 1960) o el Lexicon de Deferrari \& Barry (Catholic University of America Press, 1948). El Lexicon de Schütz (Paderborn 1895, disponible en www.corpusthomisticum.org/tl.html, como la Tabula aurea) ni siquiera los consigna.

5 Aristóteles, Política. Madrid, Gredos, 2007, I, 2, 1253a (trad. Manuela García Valdés).
} 
Desde el mismo Tomás, el tomismo ha sostenido la bondad intrínseca de la sociedad política y lo que hoy podríamos denominar el carácter "personal" del bien común político: el hombre no es sociable solamente ex indigentia, para satisfacer cierto tipo de necesidades que, en último término, se reducen siempre al propio individuo, sino sobre todo ex abundantia, en virtud de una inclinación a comunicar la perfección personal. Tal como lo ha entendido toda esta tradición del tomismo hasta hace muy poco tiempo, el bien común político es un bien honesto, no instrumental ${ }^{6}$, cuya forma más elemental es la misma vida social y cuya plenitud es una forma de $\operatorname{amistad}^{7}$.

En este contexto, siendo el bien común político el mismo bien de la persona humana en cuanto socialmente comunicado, la sociabilidad humana resulta ser inmediatamente política. Las mismas formas de asociación pre-políticas están ordenadas al orden político, de modo que sociabilidad y politicidad se relacionan como la parte y el todo. No cabe la idea de un pacto; no cabe una condición humana pre-social; la condición pre-política solo es comprensible en orden a la politicidad $y$, en consecuencia, resulta superflua la distinción entre pactum associationis y pactum subiectionis. En síntesis, no cabe nada semejante a un "estado de naturaleza”.

Al margen del modo concreto en que se designe a quien la detenta, la autoridad política es connatural a la politicidad del bien humano; de hecho, no es posible que haya sociedad política sin una forma de autoridad, porque los muchos deben actuar como uno ${ }^{8}$. Particularmente luminoso al respecto y útil para el planteamiento de este ensayo, es la respuesta de Summa Theologiae I, q.96, a.4, en que Tomás de Aquino se pregunta por la posibilidad del dominio de un hombre sobre otro en el estado de inocencia. Allí se explica que:

"El dominio se entiende de dos maneras. La primera, en cuanto se opone a la servidumbre, y de este modo domina quien tiene un siervo. La segunda, en cuanto se refiere a cualquier modo de sujeción considerado en común, y en este sentido se dice que domina quien tiene la función de gobernar o dirigir a personas libres. El dominio en el primer sentido no

\footnotetext{
${ }^{6}$ Para la discusión sobre la no instrumentalidad del bien común en Tomás de Aquino, puede ser útil Pakaluk, Michael. "Is the common good of political society limited and instrumental?", The Review of Metaphysics, 55.1, 2001, pp. 57-94.

7 La distinción entre estos motivos de la asociación (ex indigentia, ex abundantia) y la naturaleza simultáneamente formal y final del bien común respecto de la sociedad están desarrollados en mi artículo Letelier, G. "El bien común político”, en Miranda, A., y Contreras, S., Problemas de derecho natural, Santiago, Legal Publishing, 2015, pp. 413-445, al que me permito remitir. Para una síntesis particularmente profunda y eficaz sobre el bien común político, vid. Lamas, F. A. "El bien común político", en Ayuso, M. (ed.). Dalla geometria legale-statualistica alla riscoperta del diritto e della politica. Studi in onore di Francesco Gentile, Marcial Pons, 2006, pp. 305-319.

${ }^{8}$ Baste por las innumerables referencias posibles, Tomás de Aquino, De regno I, 1.
} 
se daba en el estado de inocencia, mientras que el segundo ciertamente era posible. [...] Domina uno sobre otro como libre cuando lo dirige a su propio bien o al bien común. Y este dominio de un hombre sobro otro hombre existía en el estado de inocencia, por una doble razón.

La primera, porque el hombre es naturalmente un animal social, por lo tanto, los hombres en el estado de inocencia habrían vivido socialmente. La vida social de muchos no puede darse si no hay alguien que preside y dirige al bien común, pues los muchos de por sí tienden a muchas cosas, en cambio uno, solo a una. Por esta razón dice el Filósofo, al comienzo de la Política, que cuando muchas cosas se ordenan a una, siempre hay algo que es primero y dirige" 9 .

La función propia de la autoridad es determinar el modo concreto de alcanzar el fin entre los muchos posibles. Por esta razón, su virtud propia es la prudencia ${ }^{10}$. En los términos de la escolástica española, el pecado original hace necesaria la vis coactiva de la ley, pero no el gobierno y la ley en absoluto ${ }^{11}$. Y dado que el pecado original no produce un cambio en la naturaleza, sino que se compara a ella como la enfermedad con la salud ${ }^{12}$, la vis coactiva debe ser considerada como el modo extremo y más imperfecto de la vis directiva, cuyo objeto es la conducta injusta, pues que se den o no conductas injustas de las cuales retraer mediante la amenaza de sanción es accidental respecto del fin de la autoridad política.

En fin, la propiedad privada es justa y conveniente por derecho natural secundario, derivado inmediatamente por modo de conclusión ${ }^{13}$. No cabe, en este contexto, hablar de comunidad de bienes sino de un modo precisivo y final, pero en ningún caso con un sentido histórico-empírico u originario: las cosas no pertenecen, en principio, a nadie en particular, y deben ser ordenadas al bien de todos, lo cual se realiza de modo más eficaz (pues cada uno es más solícito respecto de lo suyo), ordenado (pues se evitan confusiones) y pacífico (ya que se evitan conflictos) cuando cada uno posee lo suyo ${ }^{14}$.

La relación entre estos tres aspectos (politicidad, autoridad y propiedad) salta a la vista, pues la vida humana supone en primer lugar la satisfacción de las necesidades

\footnotetext{
9 La traducción es mía; tengo presente edición bilingüe de la BAC (Tomás de Aquino. Suma Teologíca, Madrid, BAC, 1955, tomo II, pp. 659-661).

10 S. Th. II-II, q.50, a.1, sobre la prudencia gurbernativa.

${ }_{11}$ El texto primario para esta distinción, al que remiten nuestros autores, es S. Th., I-II, q.96, a.5

12 S.Th. I-II, q.109, a.2, sobre la posibiidad de hacer y querer el bien sin la gracia. Como se sabe, es comentando este pasaje que Cayetano plantea la idea de un "estado de naturaleza pura".

13 S. Th. II-II, q.66, a.1-2.

${ }_{14}$ S. Th. II-II, q.66, a.2, in c. La argumentación es rigurosamente aristotélica; cfr. Aristóteles, Politica, op. cit., II, 5, 1263a-1264b.
} 
básicas mediante una provisión de bienes materiales que solo es posible mediante la vida social. El aspecto más básico del bien común político es precisamente este ${ }^{15}$. De hecho, buena parte del concreto dinamismo de la vida social consiste en relaciones de intercambio de bienes lícitamente apropiados y poseídos, de modo que una de las funciones principales de la autoridad política, sobre todo en su función legislativa y jurisdiccional, es la de ordenar estos intercambios. Pero - pace Saint-Simon o Marx- el gobierno de los hombres es muy distinto de la administración de las cosas: los fines de la autoridad política trascienden con mucho esta mera función "administrativa". En este esquema, en fin, la ineludible presencia del mal moral altera profundamente el modo concreto de la vida social, pero no modifica su naturaleza. Al margen del concreto status en que se considere al hombre (naturae integrae, lapsae, reparatae o incluso purae), el bien del hombre es siempre político, requiere de una autoridad que eroga leyes vinculantes para todos, y exige la posesión de bienes materiales; pero ninguno de estos rasgos depende del otro en su respectiva fundamentación y justificación.

\section{El tomismo "ortodoxo" de Vitoria y Soto}

Vitoria y Soto Reciben sin mayores cambios la concepción tomista de la politicidad natural, pero incorporan algunas precisiones importantes que denotan un profundo cambio de mentalidad. Por una parte, ambos recogen el locus commune estoico, presente en el Digesto ${ }^{16}$, según el cual los hombres nacen libres, de modo que nadie es señor de otro hombre si no por convención, constituyéndolo como principio argumental. Sin llegar a una interpretación rigurosamente individualista, el principio dialoga de modo muy cercano con una lectura humanista de los mitos clásicos sobre una edad primigenia (¿de oro?), no pocas veces considerada histórica ${ }^{17}$ y reflejada en el relato bíblico de Cam y Nemrod ${ }^{18}$, en que la vida de los hombres prescindía de toda forma de autoridad política.

El vínculo entre politicidad del hombre y autoridad es pensado ahora tanto desde la perspectiva final, relativa al bien del hombre y planteada, primero, desde la indigencia de la limitación física y, después, desde la abundancia de la comunicación

\footnotetext{
15 Cfr. Lamas, F. "El bien común político”, op. cit.

${ }^{16}$ Justiniano, Digesto I, 1, 4: “cum iure naturali omnes liberi nascerentur" (García del Corral, I. Cuerpo del Derecho Civil, Valladolid, Lex Nova, 2004, tomo I, p. 198)

${ }_{17}$ Un ejemplo cercano a estos autores es Vázquez de Menchaca, Fernando. Controversiarum illustrium aliarumque usu frequientium. Madrid, Talleres Cuesta, 1931.

18 Gen. 10, 6-9
} 
amistosa, como desde la perspectiva eficiente y material, relativa a la necesidad de unirse en sociedad civil y designar una autoridad política ${ }^{19}$. La potestas civilis es efecto de Dios, autor del derecho natural, y no de "un pacto [condicto] de los hombres o cualquier derecho positivo" ${ }^{20}$; sin embargo, lo que mueve a los hombres a unirse en sociedades y repúblicas es en primer lugar la defensa y conservación [tutela et conservatio] de su vida, "apremiante necesidad de la cual solo los dioses se sustraen ${ }^{21}$. Ahora bien, este motivo primario no agota la finalidad de la sociedad humana: cuando comenta el clásico pasaje aristotélico citado arriba, la traducción de Vitoria vierte el griego "logos" por el latín "sermo", muy próximo a nuestro "discurso", "cuyos máximos ornamentos son la justicia y la amistad" 22 , para ańadir poco después: "dado que las sociedades humanas se han constituido para este fin, esto es para que cada uno sobrelleve las cargas de los otros, y siendo entre todas las sociedades, la sociedad civil aquella que con más comodidad subviene a las necesidades de los hombres, se sigue que la sociedad es, como si dijéramos, una naturalísima comunicación en grado sumo conveniente a la naturaleza" ${ }^{23}$. Como buen tomista, Vitoria razona desde la tesis aristotélica según la cual "lo que cada cosa es una vez cumplido su desarrollo, decimos que es su naturaleza" "24: la comunicación amistosa en la virtud es forma y fin de la sociedad política; el bien común político perfecto presupone la suficiencia de los bienes necesarios para la vida, pero consiste en la comunicación virtuosa de los miembros de la comunidad ${ }^{25}$.

De modo paralelo, cobra paulatinamente cada vez más fuerza el recurso argumentativo a un pacto que, si bien no es fundante de la sociedad política, asume un carácter legitimador respecto de quien detenta el poder político en concreto. Sin embargo, la figura utilizada por Vitoria es todavía la de una delegación o mandato en De potestate civili utiliza "mandare", "deferare" y "transferire"; en el Comentario a II-II q.63 a.3 usa "mandare et committere" ${ }^{26}$ - ciertamente distinta de la suareciana

\footnotetext{
${ }_{19}$ Vitoria, F. Relectio de potestate civili: Estudios sobre su filosofía politica (ed. Cordero Pando, J), Madird, CSIC, 2008, \$\$ 1-11.

${ }^{20}$ Ibid. $\$ 6$, p. 23.

${ }^{21}$ Ibid. $\$ 5$, p. $21-23$.

22 Ibid $\$ 4$, p. 19.

23 Ibid $\$ 4$, p. 21.

${ }^{24}$ Aristóteles, Política, op. cit., I, 2, 1253a; vid. III, 6, 1278 b.

${ }^{25}$ Es muy sorprendente que, en la antología de textos políticos que acompaña su cuidada edición de la Relectio de potestate civili, Cordero Pando (op. cit.: 93) incluya como argumento, sin mayores precisiones, un texto de Vitoria correspondiente a la explicación de la (única) objeción a la tesis de $S$. Th. I-II, q.92, a.1 allí comentada, que objeta precisamente este carácter moral del bien común político. Todo el texto de Vitoria corresponde en realidad a la refutación de esta tesis; vid. Vitoria, F. De legibus (ed. Barrientos, J. y Langella, S.), Salamanca, Ediciones Universidad de Salamanca, 2010, pp. 111-117.

${ }^{26}$ Vitoria, F. Relectio de potestate civili, op. cit., pp. 30, 34, 126.
} 
renuncia o alienatio de derechos, que tiene la forma de un "consensus omnium" muy cercano a la lectura tomista de la concordia política aristotélica ${ }^{27}$, que es una forma de amistad: se trata, en efecto, de la volición genérica de un bien común a todos por parte de la comunidad constituida como tal, y no de un acto discreto de elección atribuible a una multitud. La amistad es forma y es fin.

Tal como se manifiesta en el mismo De potestate civili 15-19, en el comentario a S. Th. I-II, q.96 a.4, de Vitoria, y en el De iustitia et iure I q.6, especialmente a.4, de Soto, la explicación de la obligación jurídica sigue en todo a la de Tomás de Aquino. Entre las múltiples diferencias de matiz que se pueden hallar comparando estos textos, la única relevante para nuestro propósito es precisamente la tematización explícita del problema, que, nuevamente, nos ubica en el umbral del surgimiento de una nueva sistematización de la ética, que desplaza su centro desde la virtud hacia la ley ${ }^{28}$. Para el tiempo de Suárez, este giro está ya consumado.

La evolución del concepto de propiedad privada, por su parte, parece ser paralela e independiente del problema de la sociabilidad humana, pero se vincula muy íntimamente al de la naturaleza de la autoridad política. En efecto, según el decurso descrito en el pionero estudio de Paolo Grossi ${ }^{29}$, propiedad privada y autoridad política terminan siendo reunidas bajo el único género del dominium. De modo muy significativo, Vitoria plantea la distinción en su comentario In Secundam secundae, al comentar la cuestión relativa a la restitución (S. Th. II-II, q.62), acto propio de la justicia conmutativa, no en la relativa al hurto, donde Tomás de Aquino propone la citada justificación de la propiedad privada (S. Th. II-II, q.66). También Soto, por su parte, trata el problema del dominium al introducir el tema de la justicia conmutativa, en el marco del libro IV De iustitia et iure (q.3, a.1) $)^{30}$, en el que desarrolla lo esbozado en su Relectio de dominio. Vitoria parece haber tenido en mente precisamente la necesidad de aclarar la equivocidad de un uso común que venía identificando dominium y ius, causando importantes confusiones. Su ar-

\footnotetext{
${ }_{27}$ Para el concepto de homonoia, vid. Aristóteles, Ética Nicomaquea, Madrid, Gredos, 1993, VIII, 1155a 24-25; IX, 1167a 21-1167b 15, en especial 1167b 1-4; Ética Eudemia VII, 1241a-1241b 10. El mejor estudio sobre el tema del que tengo conocimiento es Lamas, F. "La concordia política”, en http://www.viadialectica.com/ material_didactico/concordia_politica.html (consultado el 15 de septiembre de 2020); puede verse también Klonoski, Richard J. "Homonoia in Aristotle's Ethics and Politics", History of Political Thought, 17.3, 1996, pp. 313-325.

${ }^{28}$ Para este giro que experimenta la teología moral católica postridentina, es referencia obligada el clásico Pinckaers, Servais. Las fuentes de la moral cristiana: su método, su contenido, su historia. Pamplona, Eunsa, 1988.

29 Grossi, P., "La propietà nel sistema della seconda scolastica", La seconda scolastica nella formazione del diritto privato moderno, Torino, Giuffrè, 1973, pp. 117-222. Las tesis de Grossi, ciertamente, han sido ampliamente discutidas y, en varios puntos, matizadas o corregidas; pero la matriz básica descrita en el texto sigue siendo canónica y la referencia, obligada.

${ }^{30}$ Soto, D. De la Justicia y del Derecho (trad. de M. González), Madrid, Instituto de Estudios Políticos, 1967.
} 
gumentación es perfectamente compatible con la doctrina de Tomás de Aquino ${ }^{31}$, que usa ampliamente el término dominium sin establecer ningún vínculo con los sentidos propios del término ius; pero al distinguir, concede: en adelante, ambas instituciones - propiedad privada y autoridad política- quedan unificadas bajo la noción extremadamente amplia de dominium.

A esta paulatina aproximación terminológica se añade otra previa, de género muy diverso, originada en un difundido agustinismo político cuya principal contraparte era precisamente la escuela tomista, según la cual tanto la autoridad política como la propiedad privada debían ser consideradas como consecuencias del pecado original. Discípulos de Tomás de Aquino, tanto Vitoria como Soto niegan rotundamente que el pecado original tuviera una incidencia relevante en la naturaleza y origen del poder político, aunque sí la tenga, y muy relevante, en su concreta necesidad y ejercicio. El pecado no causa el poder político, porque este es natural, ni lo obstaculiza, porque también los infieles tienen autoridades legítimas; pero lo cierto es que la mayor parte de los hombres son "protervos e inclinados al vicio", y no son conducidos a la virtud sino por el temor de la sanción ${ }^{32}$. Aunque se niega la conclusión, se conceden $-\mathrm{y}$ los jesuitas posteriores, como Mariana, enfatizan- las premisas para fundar el poder político en una maldad humana que autores modernos, como Hobbes o Locke, dejarán de concebir como efecto de un pecado y asumirán como mero dato natural ${ }^{33}$, quitándole, de este modo, su carácter de culpabilidad. La propiedad privada, por su parte, es presentada por Soto como efecto del pecado original (IV, q.3, a. único).

\section{Suárez y el tránsito al pensamiento moderno}

TAMbién SuÁreZ aFirma enfáticamente la pOliticidad NATURAL DEL HOMbre, remitiendo a Aristóteles y Tomás de Aquino, pero ahora con importantes matices. Según un modo de razonamiento que Esposito considera arquetípicamente barroco ${ }^{34}$

\footnotetext{
31 Tal como lo mostró Brufau Prats, J. "La noción analógica del dominium en Santo Tomás, Francisco de Vitoria y Dominingo de Soto", La Escuela de Salamanca ante el descubrimiento del nuevo mundo, Salamanca, San Esteban, 1989.

32 S. Th. q.95, a.1, sobre la necesidad de la ley humana. Vid. I-II, q.92, a.1 y el respectivo comentario de Vitoria (De legibus, op. cit.) y de Soto (De Iustitia et iure, op. cit., I, II, 1).

33 Para Hobbes (como para Rousseau, aunque de modo distinto), más que ser malo, el hombre natural carece de sentido moral; tampoco Locke atribuye las eventuales discordias superadas por el pacto a la maldad.

34 Esposito, C. “Suárez, filósofo barroco”, Cauriensia XII, 2017, pp. 25-42, doi: https://doi.org/10.17398/18864945.12.25
} 
y que De Muralt remite a la distinctio formalis ex natura rei del escotismo ${ }^{35}$, Suárez distingue muy claramente los diversos aspectos formales de las cosas, considerándolos de modo separado (distintos ex natura rei), para volver a reunirlos en una síntesis unitaria.

Con este procedimiento, tiende a aparecer en Suárez una artificialidad del orden político mucho más definida ${ }^{36}$. Allí donde no ha habido instauración de un régimen específico mediante un pacto, hay ya uno por defecto: el democrático, que, siempre según De Muralt, constituiría el antecedente más directo del moderno "estado de naturaleza". Asimismo, la descripción analítica de los diversos elementos del orden político, que, siendo distintos ex natura rerum, pueden darse también de modo separado, tienden a asumir la forma de -o al menos ser compatibles conuna descripción de un desarrollo histórico, que comienza con la familia y termina en el orden político. Su discusión sobre un eventual poder político de Adán ${ }^{37}$ es retomada sin mayores diferencias por Locke ${ }^{38}$, autor que lo sigue muy de cerca en muchos aspectos centrales ${ }^{39}$.

En este contexto, no solo es pensable un momento hipotético en el que solo está vigente la ley natural; la idea de natura pura es constituida como presupuesto teórico de la filosofía práctica ${ }^{40}$ y deviene plenamente legítima la pregunta por la historicidad de la condición pre-política, de la cual se sale mediante una alienatio de derechos entendida como un acto discreto de la voluntad, es decir una elección, incluso allí donde es tácito. La distinción es relevante en muchos sentidos. En el citado pasaje de Aristóteles sobre la sociabilidad natural del hombre, el tomismo leyó una cierta identidad entre los principios eficiente, formal y final del orden político, entendidos como plenitud del bien humano. Si ya Vitoria enfatizaba la dimensión útil de la asociación civil, ex indigentia, Suárez directamente pone un acto electivo cuyo objeto es la asociación. La amistad política, plenitud del bien común político, es ahora un bien ulterior y distinto ${ }^{41}$. Como sus contemporáneos, Suárez

\footnotetext{
35 De Muralt, op. cit..

36 El lugar de referencia, por supuesto, es el libro III de su Defensio Fidei, en especial los cinco primeros capítulos, relativos al Principatus politicus en cuanto tal (Suárez, F. Defensa de la Fe (trad. de J. R. Eguillor). Madrid, Instituto de Estudios Políticos, 1970.

37 Suárez, F. Las Leyes (trad. de J. R. Eguillor). Madrid, Instituto de Estudios Políticos, 1967, III, 2, 3.

38 Locke, J., op. cit., First book, passim

39 Aunque debería ser superfluo decirlo, esta proximidad es, evidentemente, de Locke respecto de Suárez, y no viceversa; una muy buena descripción de esta influencia en Baciero, F. "El De Legibus de Suárez y Locke”, Revista española de filosofia medieval 10, 2003, pp. 387-393.

40 Es la tesis de Courtine, Jean-François. Nature et empire de la loi: études suaréziennes, Paris, Vrin, 1999 y de Todescan, Franco. Lex, natura, beatitudo, Padova, Cedam, 1973.

41 El problema de la amistad política está notoriamente ausente en los autores del período.
} 
no tematiza la amistad sino en el contexto de la caridad ${ }^{42}$, pero mientras Vitoria todavía describía bastante incidentalmente -es decir, como algo bastante evidente y natural- el bien de la vida social en términos de communicatio, ya el mismo Locke pudo leer el De Legibus de Suárez con marcados acentos individualistas.

En la formulación de Suárez, el bien común político solo se hace efectivo de modo concomitante con el surgimiento de la autoridad, pues los individuos miran sobre todo a sus intereses particulares:

"Cada uno de los miembros particulares mira por su conveniencia particular, la cual muchas veces es contraria al bien común, y a veces hay muchas cosas que son necesarias para el bien común, las cuales no son tan necesarias para cada uno de los particulares, y aunque a veces sean necesarias no se procuran porque sean de interés común sino porque son de interés particular, luego en una comunidad es necesario el poder público al cual por oficio corresponda buscar y procurar el bien común” ${ }^{43}$.

Sin embargo, este bien común político sigue siendo superior e irreductible al bien de los individuos, incluyéndolo como el todo a la parte. Aun así, la diferencia de tono y de énfasis salta a la vista cuando se compara el razonamiento de Tomás de Aquino, en $S$. Th. II-II, q.47, a.10, ad 2, respecto del modo en que se debe considerar el bien del hombre en cuanto miembro de la comunidad:

"Aquel que quiere el bien común de la multitud quiere también en consecuencia el bien suyo, por dos razones. Primero, porque el bien propio no puede existir sin el bien común, sea de la familia, de la ciudad o del reino. Por lo cual Máximo Valerio dice de los antiguos romanos que 'preferían ser pobres en un imperio rico que ricos en un imperio pobre'. Segundo, porque, por ser el hombre parte de la casa y de la ciudad, es menester que considere qué es lo bueno para él teniendo en cuenta qué es lo prudente respecto del bien de la multitud: pues, en efecto, la buena disposición de las partes se juzga de acuerdo a su relación al todo. Por esto Agustín dice, en el libro de las Confesiones, que 'es deforme aquella parte que no está en congruencia con su todo"'.

respecto de la argumentación de Suárez sobre el mismo problema:

"Añado -en tercer lugar- que el poder civil legislativo, aun considerando el estado de pura naturaleza, no tiene por fin intrínseco y pretendido en sí mismo la felicidad natural de la vida futura, más aún tampoco la felicidad natural propiamente dicha de la vida presente en cuanto que se refiere a cada uno de los hombres como personas particulares, sino que su fin es la felicidad natural de la comunidad humana perfecta, cuyo cuidado tiene, y de cada

\footnotetext{
42 Vid. Suárez, F. De Charitate, Paris, Vivès, 1855, tomo 12.

43 Suárez, F. Las Leyes, op. cit., III, 1, 5, p. 199.
} 
uno de los hombres como miembros de esa comunidad, a fin de que vivan en ella en paz y justicia, con suficiencia de los bienes que sirven para la conservación y comodidad de la vida corporal, y con la rectitud de costumbres que es necesaria para esa paz y felicidad externa del estado y para la conveniente conservación de la naturaleza humana" ${ }^{44}$.

Allí donde Tomás de Aquino sostiene que quien busca el bien común halla su propio bien, Suárez afirma exactamente lo mismo, pero planteado de modo inverso: la felicidad de la comunidad es lo que permite que los hombres singulares vivan con costumbres rectas y en paz.

En rigor, el mismo Suárez excluye la lectura individualista al situar el bien común político, junto a toda la tradición del tomismo, en la virtud ciudadana, que es fin de la ley ${ }^{45}$. En efecto, Suárez considera evidente que la ley no mande la totalidad de la virtud ni prohíba todos los vicios, no porque no se ordene a la virtud, sino porque, "según el dicho vulgar, el fin de la ley no cae bajo la ley" " ${ }^{6}$. Por esta razón, la misma sociedad civil es un bien honesto, no instrumental, que se ordena, como afirma en una obra teológica, a la comunicación personal: "esta comunidad de vida es deseable no solo por la necesidad de ayuda mutua, sino por sí misma, para mayor gozo de la vida y de una honesta comunicación, que el hombre naturalmente ama" ${ }^{47}$.

Como el fin de la asociación es un bien honesto realmente común a muchos, según una concepción del bonum rigurosamente clásica ${ }^{48}$, el acto por el que se ama este fin no es idéntico al acto por el que se elige la asociación. A diferencia de lo que sucede, por ejemplo, en Locke ${ }^{49}$ (pero también en Hobbes ${ }^{50}$ o en Rousseau $^{51}$, por los motivos que expone De Muralt ${ }^{52}$ ), para quien la voluntad no es

${ }_{44}$ Suárez, F. Las Leyes, op. cit., III, 11, 7, 238.

45 Suárez, F. Las Leyes, op. cit., I, 12, 9.

46 Ibid., p. 67

47 Suárez, F. De opere sex dierum, Paris, Vives, 1855, tomo 3, V, 7, p. 415.

48 Suárez, F. Disputationes Metaphysicae, Paris, Vives, 1855, tomo 25, Disp. 10, sec. 1.

49 Locke. J. An essay concerning human understanding. Oxford, Oxford University Press, 1975, II, \$\$ 20-21.

${ }^{50}$ Hobbes. T. Elements of Law, natural and civil, London, John Bohn, 1839-1845, IV, p. 69: "Appetite, fear, hope, and the rest of the passions [...] proceed not from, but are the will; and the will is not voluntary: for a man can no more say he will will, than he will will will, and so make an infinite repetition of the word; which is absurd, and insignificant"

${ }^{51}$ J.J. Rousseau, por su parte, seńala que "Chaque acte de souveraineté, ainsi que chaque instant de sa durée, est absolu, indépendant de celui qui précède; et jamais le souverain n'agit parce qu'il a voulu, mais parce qu'il veut” (fragmento inédito del Manuscrito de Ginebra, versión preliminar del Contrat Social, en C.E. Vaughan, The Political Writings of Jean-Jacques Rousseau, Cambridge University Press, Cambridge 1915, i, p. 311).

52 Op. cit. Perfectamente en línea con De Muralt, Lucien Jaume observa un “sorprendente parallelismo” entre el citado fragmento de Rousseau y el "instantaneismo" del cogito cartesiano en las Meditaciones Metafísicas (cfr. Jaume, L. "Rousseau e la questione della sovranità", en G. Duso [ed.], Il potere, Carocci, Roma 1999, p. 186, 
una facultad, sino un acto singular, la volición del bien común no es una elección, sino más bien una intentio o inclinatio fundada en fines amados naturalmente. En consecuencia, el acto de elección de la autoridad y de la misma asociación no es idéntico al acto de volición del bien común político. Por esta razón, la eventual historicidad del pacto es una posibilidad abierta que no es necesario precisar. De hecho, la voluntad de los individuos considerados como tales es incapaz de engendrar un orden político:

"este poder natural de dar leyes humanas no se da en los hombres considerados individualmente ni en una multitud agregada sólo accidentalmente, sino en la comunidad en cuanto unida moralmente y ordenada a formar un cuerpo místico, del cual resulta como una propiedad suya" ${ }^{53}$.

Este corpus mysticum es una comunidad real, con unidad de orden en virtud de su fin, cuyas relaciones internas, en consecuencia, no pueden ser entendidas simplemente desde la obligación, la ley o los derechos individuales, sino solamente desde los fines comunes:

"Para entender mejor esto hay que advertir que a la multitud humana se la puede considerar bajo dos aspectos. El primero, sólo como un conglomerado sin ningún orden ni unión física ni moral; de esta manera los hombres no forman una unidad ni física ni moral y por eso tampoco son propiamente un cuerpo político y por consiguiente no necesitan de una cabeza ni de un soberano; por eso si se considera a los hombres bajo este aspecto todavía no se concibe en ellos este poder en su sentido propio y formal sino a lo sumo como quien dice radicalmente.

A la multitud humana pues hay que considerarla bajo otro aspecto, en cuanto que, por un deseo especial o consentimiento general, se reúnen en un cuerpo político con un vínculo de sociedad y para ayudarse mutuamente en orden a un fin político, de la misma manera que forman un cuerpo místico que moralmente puede llamarse uno por su naturaleza; ese cuerpo en consecuencia tiene necesidad de una cabeza. En una comunidad así, como tal, por la misma naturaleza de la cosa, se da este poder, de tal manera que no está en manos de los hombres reunirse de esa forma e impedir este poder" 54

En síntesis, aunque nunca la tematiza y pocas veces la alude explícitamente, permanece en Suárez plenamente vigente y operativo lo esencial de la lectura tomista de la idea aristotélica de homonoia o concordia política: una volición común,

nota 31). En realidad, como demuestra De Muralt, todo esto se hace mucho menos sorprendente en cuanto se repara en las comunes raíces nominalistas de la filosofía moderna.

53 Suárez, F. Las Leyes, op. cit., III, 11, 7, p. 238.

54 Suárez, F. Las Leyes, op. cit., III, 2, 4, pp. 202-203. 
indeterminada y no electiva, del bien común político, que opera como principio de unidad del cuerpo social y exige, en consecuencia, la existencia de una autoridad que determine los modos concretos de alcanzar ese bien.

Es este bien, y no el pacto, los derechos subjetivos, la autoridad o la obligatoriedad de la ley lo que explica la vida política. Y si bien es posible identificar un cierto sesgo hacia el bien individual, paralelo a un pesimismo antropológico bastante difundido en el pensamiento jesuita de la época ${ }^{55}$, la propiedad privada sigue siendo un tópico significativamente ausente de la fundamentación suareciana del poder político.

Como es sabido, Suárez tematiza muy explícitamente el problema de la obligatoriedad de la ley, otorgándole un lugar central en su discusión sobre la ley en general (materia del libro I de su Tractatus, significativamente titulado de Legibus ac Deo legislatore), inmediatamente después de haber discutido, en los doce primeros capítulos, sobre el concepto de ley y, en el capítulo XIII, sobre el efecto intentado por la ley, que es hacer buenos a los súbditos, es decir, que sean virtuosos. Esta obligación, según Suárez, es el efecto próximo y adecuado de la ley; esto significa que toda ley, y solo la ley, no hace otra cosa más que obligar, constituyéndose, de este modo, como noción cardinal de su filosofía práctica. Pero incluso esta misma obligación solo resulta inteligible desde la noción de un bien convertible con el ente, que es perfección anterior a la voluntad que lo apetece y que es realmente comunicable.

Para los efectos de este ensayo, la interminable controversia sobre el voluntarismo de la noción suareciana de ley, no ya resuelta, sino meramente constatada, manifiesta hasta qué punto es posible entender -modernamente- la obligatoriedad de la ley en la línea de la "voluntas obligandi", remontando esta misma "voluntas" hasta aquella que instituyó la autoridad, $\mathrm{y}$, al mismo tiempo -de modo manifiestamente pre moderno- seguir incluyendo en la esencia de la ley el orden al bien común ${ }^{56}$, entendido en total continuidad con la tradición tomista.

De este modo, concluyendo, parece necesario restringir la manifiesta continuidad entre el pensamiento de Suárez con Locke (o Grocio o Kant) al ámbito peculiar de la historia de la filosofía, cuyo método es forzosamente retrospectivo y, en muchas ocasiones (como en esta), bastante indiferente a la consistencia y coherencia sistemáticas de las ideas cuya genealogía traza. Mientras tanto, en un ámbito estrictamente teorético, Suárez sigue plenamente instalado en un orden de clara inspiración tomista.

\footnotetext{
55 Vid. Höpfl, Harro. Jesuit Political Thought, Cambridge, Cambridge University Press, 2004.

${ }^{56}$ Suárez, F. Las Leyes, op. cit., I, 7.
} 


\section{Conclusión}

A ESTAS ALTURAs, LA IDEA DE UNA SITUACión FRONTERIZA de la escolástica española, y especialmente de Francisco Suárez, entre el mundo clásico y medieval y el mundo moderno, ha llegado a ser un lugar común. Estudios recientes han permitido identificar una importante influencia de Suárez en la obra de Locke, no solo respecto de ciertas tesis comunes con la escuela (p. ej., la oposición al derecho divino inmediato de los reyes, la igualdad y libertad originales de todos los hombres, la legitimación de la autoridad por un acto voluntario cuya forma es una alienatio irrevocable que, sin embargo, no excluye el derecho a rebelión) sino incluso respecto de la estructura argumental de muchos razonamientos.

Los mismos autores del periodo tenían una profunda conciencia del cambio de época que vivían, aunque, naturalmente, no terminaban de percibir qué tipo de mundo estaban anticipando. Sin embargo, su manifiesta contribución a la configuración del mundo moderno no los hace "modernos". Y así, parafraseando el cliché, si es verdad que se los debe situar a caballo entre dos mundos, habría que imaginarlos, sin embargo, elegantemente montados con ambas piernas al mismo lado. En efecto, mientras nos mantenemos en el marco de una metafísica de matriz latamente realista, las diferencias entre ellos y las semejanzas con los autores modernos, con toda la importancia que cabe reconocerles, no resultan determinantes.

Un modo, entre muchos otros, de constatar este punto, es precisamente notando cómo la tesis -metafísica- de un bien objetivo realmente comunicable permite articular en una filosofía práctica extremadamente matizada y compleja una serie de tópicos que, en cambio, en el momento y en la medida en que el bien humano deja de ser entendido como una perfección realmente comunicada, y comienza a concebirse dentro de una coordinación de fines individualmente apetecidos, confluyen en un único problema, cuya respuesta pretende dar razón de la totalidad del orden social jurídico y político. Allí donde desaparece del horizonte práctico la idea de un bien (realmente) común, entonces la causa de la asociación, fin de la autoridad política, fundamentación de la obligatoriedad y tutela de la propiedad privada vienen a ser distintos nombres de lo mismo. 


\section{REFERENCIAS BibLIOGRÁFICAS}

Aquino, Tomás de, Opera omnia, www.corpusthomisticum.org.

Aristóteles, Politica, Madrid, Gredos, 2007. Ética Nicomaquea, Madrid, Gredos, 1993.

Baciero, Francisco, "El De Legibus de Suárez y Locke”, Revista española de filosofía medieval 10, 2003.

Bérgamo, Pedro de, Tabula aurea, Paoline, 1960.

Brufau Prats, Jaime, La Escuela de Salamanca ante el descubrimiento del nuevo mundo, Salamanca, San Esteban, 1989.

Courtine, Jean-François, Nature et empire de la loi: études suaréziennes, Paris, Vrin, 1999.

De Muralt, André, La estructura de la filosofía politica moderna, Madrid, AKAL, 2002.

Deferrari, Roy y Barry, Inviolata M., A Lexicon of Saint Thomas Aquinas, The Catholic University of America Press, 1948.

Esposito, Costantino, "Suárez, filósofo barroco", Cauriensia XII, 2017.

Grossi, Paolo, "La propietà nel sistema della seconda scolastica", en La seconda scolastica nella formazione del diritto privato moderno, Torino, Giuffrè, 1973.

Hobbes, Thomas, Elements of Law, natural and civil, London, John Bohn, 18391845.

Höpfl, Harro, Jesuit Political Thought, Cambridge, Cambridge University Press, 2004.

Jaume, Lucien, "Rousseau e la questione della sovranità", en Duso, G. (ed.), Il potere, Roma, Carocci, 1999.

Justiniano, Digesto, "Cuerpo del Derecho Civil", Valladolid, Lex Nova, 2004.

Klonoski, Richard J., "Homonoia in Aristotle's Ethics and Politics", History of Political Thought 17.3, 1996.

Lamas, Félix A., "El bien común político”, en Ayuso, M. (ed.). Dalla geometria lega-le-statualistica alla riscoperta del diritto e della politica. Studi in onore di Francesco Gentile, Madrid, Marcial Pons, 2006. 
Letelier, Gonzalo, "El bien común político", en Miranda, A. y Contreras, S. (eds.), Problemas de derecho natural, Santiago, Legal Publishing, 2015.

Locke, John, Two treatises of government, Cambridge, Cambridge University Press, 2015.

Press, 1975.

. An essay concerning human understanding, Oxford, Oxford University

Pakaluk, Michael, "Is the common good of political society limited and instrumental?", The Review of Metaphysics 55.1, 2001.

Pinckaers, Servais, Las fuentes de la moral cristiana: su método, su contenido, su historia, Pamplona, Eunsa, 1988.

Rousseau, Jean-Jacques, The Political Writings of Jean-Jacques Rousseau, Cambridge, Cambridge University Press, 1915.

Schütz, Ludwig, Thomas-Lexikon, Paderborn, 1895.

Soto, Domingo de, De la Justicia y del Derecho, Madrid, Instituto de Estudios Políticos, 1967.

Suárez, Francisco, Defensa de la Fe, Madrid, Instituto de Estudios Políticos, 1970.

. Las Leyes, Madrid, Instituto de Estudios Políticos, 1967.

. De Charitate, Paris, Vivès, 1855.

. De opere sex dierum, Paris, Vivès, 1855.

. Disputationes Metaphysicae, Paris, Vivès, 1855.

Todescan, Franco, Lex, natura, beatitudo, Padova, Cedam, 1973.

Vázquez de Menchaca, Fernando, Controversiarum illustrium aliarumque usu frequientium, Madrid, Talleres Cuesta, 1931.

Vitoria, Francisco de, Relectio de potestate civili. Estudios sobre su filosofía politica, Madrid, CSIC, 2008.

. De legibus, Salamanca, Ediciones Universidad de Salamanca, 2010.

Widow, Juan Antonio, "Escritos políticos de santo Tomás de Aquino", Estudios Públicos 57, 1995.

DOI: https://doi.org/10.15366/bp2021.26.007

Bajo Palabra. II Época. No26. Pgs: 141-160 
